\title{
Una obra olvidada de Rubén Dario
}

La contribución de Rubén Darío a Guatemala Ilustrada (1892-1894) no es $\tan$ extensa, por supuesto, como la incluida en El Correo de la Tarde (1890-1901); pero contiene, además de un trabajo en prosa no mencionado en las bibliografías del poeta, algunas de sus obras más conocidas, contándose sin duda entre lo mejor de la revista. Su colaboración más numerosa es, como podía esperarse, en verso, y se inicia desde el primer número con los entonces inéditos dodecasílabos de "Leda", reproducidos unos meses después en La Hoja del Pueblo, de Costa Rica, el 18 de noviembre de 1892, y más adelante en otras publiccciones como la Revista Azul (3 de mayo de 1896) antes de aparecer en Cantos de vida y esperanza (1905). En números posteriores van incluyéndose las poesías siguientes: "Canciones de España. A la seguidilla", así titulada todavía en la Revista Azul (9 de diciembre de 1894), pero dada al público en Prosas profanas (1896) con su título consagrado de "Elogio de la seguidilla"; "En un álbum", que no contiene ninguno de los libros publicados en vida de Darío, y conserva este título en las revistas El Fígaro, de La Habana (19 de noviembre de 1983), y Pluma y Lápiz, de Santiago de Chile (19 de octubre de 1902), entre otras, si bien aparecerá en Baladas y Canciones $(1923)^{1}$ con su título actual de "Como palomas"; "Pórtico", los famosos serventesios dactílicos para el libro En tropel (1892), de Salvador Rueda, que ya había publicado La Ilustración Ibérica, de Barcelona (26 de noviembre de 1892) y reproduciría más tarde la Revista Azul (28 de julio de 1895) y antes de ser incluido en Prosas profanas; y "Los centauros", impreso con anterioridad en $E l$ Figaro (agosto 28 de 1892) y el Almanaque Péuser para el año 1893 (Buenos Aires, 1892), antes de formar parte de Prosas profanas con el nuevo título de "Palimpsesto".

1 Vol. 0 de las Obras completas de Rubén Dario, Madrid, 1923, editadas por A González Blanco y A. Ghiraldo.

2 "Leda" (Guatemala Ilustrada, I, No. 1, 1892, p. 4); "Canciones de España: A la seguidilla" (No. 11, p. 125); "En un álbum" (No. 12. p. 139); "Pór- 
Su aporte en prosa consta de tres trabajos. El primero es de carácter poemático con cierta influencia de Poe, como atestiguan su título "Never More" y algunas alusiones a la famosa poesia "El Cuervo". Presentado el poema en tres visiones, se reconocen en ella la juventud con su plétora de esperanzas; el triunfo, acaso de la madurez, con su retribución de oro y palmas; y el desengaño final, con su acompañamiento de negruras, ayes y sollozos. A nuestro entender, "Never More" es una producción hasta ahora desconocida, u olvidada, del poeta, ya que no se encuentra en las ediciones de sus obras completas ni en las varias colecciones de trabajos inéditos o de juventud. ${ }^{3}$ De modo que, más por su rareza que por su mérito literario, la reproducimos a continuación:

\author{
"Never More...! \\ A mi amigo José Tible Machado
}

\title{
(Inédito)
}

Triste, con la tristeza alegre que suele venir en las borracheras - no bajo el influjo de la musa verde, no bajo el influjo de la musa negra; sino bajo tu influjo joh suave musa! que derramas lágrimas y me consuelas--, yo estaba pensando.

La primera visión fue el ayer; la hermosa juventud, rosada y florida, llena de sol, poblada de todas las alegrías de la primavera.

Allá lejos, Io que resplandecía, era la aurora; la palabra que me murmuraba una voz al oído era: "Esperanza".

La segunda visión fue toda de oro, radiante en la apoteósis triunfal del Emperador-sol; un relámpago de diamantes, una fiesta de iris vivos, un supremo esplendor de infinitas claridades era el fondo de la visión, iy la visión era una palma de luz, símbolo del triunfo! emblema de la posesión del hoy glorioso que me ha-

tico" (No. 13, p. 151). Esta composición se inserta en una reseña de En tropel, pp. 151-153. "Los centauzos" (I, No. 26, 1893, pp. 305-306). Las fechas de las revistas mencionadas son el producto de investigaciones propias y ajenas. Dos obras de utilidad para algunas de las revistas de la América del Sur y de España fueron: Bibliografía de Rubén Dasto, Santiago de Chile, 1946 de Julio Saavedra Molina y Rubén Darío y el modernismo en España, New York, 1968, de Carlos Lozano.

3 Tampoco la menciona el profesor John E. Englekirk al referirse a Darío en su valioso estudio Edgar Allan Poe in Hispanic Litenature, New York, 1934. 
cia mirarme como un rey "que acabara de recibir la herencia de un trono y cuyo nombìe fuera saludado por salvas de cañones y estallidos de clarines.

La tercera visión tenía un fondo negro y obscuro: era una enlutada y pálida criatura que tenía las manos juntas y los ojos tristes. En la profundidad de la noche, había ecos de sollozos, estremecimientos, ayes; $y$ de pronto, en una fúnebre claridad de luz difunta, en algo como el sereno esplendor de un fatal sueño, la voz de la pálida criatura, vaga y amarga, como llena de gemido, me dijo la palabra que oyó del Cuervo, Edgar Poe: —Jamás...

RUBÉN DARÍO

La segunda colaboración en prosa de Darío es una de sus menos nombradas semblanzas españolas "Los Maestros: Núñez de Arce", en la que se narra una visita al poeta vallisoletano y se hacen comentarios sobre algunas de sus obras. Esta semblanza ha sido incluida en el tomo I de las Obras completas de Dario, publicadas por Afrodisio Aguado en Madrid, en 1950; pero sufre varias modificaciones en comparación con el texto de Guatemala Ilustrada, así como la omisión de dos párrafos de regular extensión entre las secciones III y IV. He aquí esos párrafos:

"La Visión de Fray Martín", en mi sentir, el mejor poema de mi querido y noble amigo, quedaría bien intercalada entre los mejores frescos de este cíclico monumento de "La Leyenda de los Siglos". No es que la factura de la obra se resienta de victorhuguismo. Antes bien, todo el ambiente, los personajes todos, parecen ser del único poeta francés con quien puede compararse Núñez de Arce, Leconte de Lisle. El abate Hierónimus tiene parentesco cercano con el Lutero del maestro español. El modo de tratar el asunto, la encarnación casi visionaria de los frailes, el soplo conventual, las arengas teológicas y místicas, la lucha... por allí pasó el mismo "decir"! Núñez de Arce y Leconte de Lisle son grandes y fraternales. El español no es imposible [¿impasible?] como aquél a quien el Dios Hugo dijo: "jungamos deetrás" [sic].

El francés, sabio y calvo, no conoce ni ha sentido el roce dulce de las alas de la divina Psiquis. Es el vate sacrocesáreo, pon-

4 Guatemala Ilustrada, I, No. 2, 1892, p. 16. 
tifical, hierático que quema su incienso y oficia en el altar de una bella diosa sin corazón. El español tiene el alma, el gemido, la imprecación, el amor, posee a Psiquis. Arconte, pontífice, presti. gioso rimador de las formas y los colores, petrificador de ideas y de símbolos, Leconte de Lisle no baja de su torre de oro, de su elefante, si no es alguna noche, a ver a los elfos coronados de tomillo y de mejorana. Núñez de Arce desciende de su castillo medioeval, de la iglesia antigua, para conducirnos a la vida emocional de la idea, o a darnos los húmedos diamantes de las lágrimas en la faz rosada de esa pobre muchacha encantadora que se llama ¿Melisendra? no: ¿Maruja? [sic] ${ }^{5}$

En contraste con la relativa anonimidad de la semblanza anterior al tercer trabajo en prosa, que resulta la última colaboración de Darío a la revista, es el bello y conocido cuento " $\mathrm{La}$ muerte de la emperatriz de la china". Escrito al parecer en San Salvador en 1889, ${ }^{\circ}$ llegó a la letra impresa en La República, de Santiago de Chile, el $1^{\circ}$ de mayo de 1890, reaparece al mes siguiente en El Perú Ilustrado de Líma, el 5 de junio de 1890 , y se incluye por fin en la segunda edición de $A z u l$, impresa en Guatemala en octubre del mismo año. ${ }^{7}$

\section{Tulane University. \\ Thlane Universily.}

Otto Olivera

- Ibid., I, No. 21,1893 , p. 244. Para la semblanza completa véase pp. 243-245.

6 G. Alemán Bolaños La juventud de Rubén Dario, Guatemala, 1923, p. 141. p. 127.

7 Ernesto Mejía Sánchez, Cuentos completos de Rubén Dario, México, 1950, 